Красноборов Михаил Андреевич

аспирант, преподаватель кафедры культурологии Пермского государственного

гуманитарно-педагогического университета

\section{УПРАВЛЕНИЕ ФОРМИРОВАНИЕМ ТЕРРИТОРИАЛЬНОЙ ИДЕНТИЧНОСТИ В РАМКАХ КОНСТРУКТИВИСТСКОГО ПОДХОДА ПЬЕРА БУРДЬЕ}

\section{Аннотация:}

В статье предпринята попытка использовать концепцию конструктивизма, берущую свое начало в трудах П. Бергера, Т. Лукмана и получившую развитие в теориях структурного конструктивизма П. Бурдье и генеалогии власти М. Фуко, как методологический принцип социологии управления. В соот ветствии с этими концепциями, суть управления состоит в монополии на установление символических систем классификаций и иерархий, результатом чего является конструирование социальных групп и формирование их идентичности. Идентичность представляет собой сложное социальное и культурное явление, включающее в себя большое количество представлений, которые отражают восприятие и оценку прошлого и настоящего во всем его многообразии, характерном как для общества в целом, так и для отдельных социальных групп. Согласно современным теориям управления, культура является важным ресурсом в сфере развития любой обиности, в том числе территориальной, институциональной, профессиональной и m. д. В данном случае под культурой понимаются символические системы, обеспечивающие взаимодействие социальных субъектов. По мнению П. Бурдье, одной из важнейших частей управления является реализация символической власти в области установления социальных классификаций и иерархий. Идентич ность, на основе которой создается социальная обиность и в фундаменте которой лежит историческая память, с одной стороны, является результатом действия символических систем государственных институтов, а с другой, сама порождает другие символические системы, на которых строятся символическая политика городов, школьное и вузовское историческое образование, политика ис тории и многое другое. Таким образом, включение проблематики территориальной и локальной идентичности в поле социологии управления способствует расиирению представлений об уровнях и инструментах управленческих практик.

Ключевые слова:

власть, символические системы, дискурсивные практики, телесные практики, габитус, конструктивизм, управление, территориальная идентичность, Пьер Бурдье.
Krasnoborov Mikhail Andreevich

PhD student, Lecturer, Cultural Studies Department, Perm State University of Humanities and Education Science

\section{MANAGEMENT OF THE FORMATION OF TERRITORIAL IDENTITY IN FOCUS OF PIERRE BOURDIEU'S CONSTRUCTIVISM}

Summary:

The article is devoted to the concept of constructivism created by $P$. Berger and T. Luckmann and developed in the structural constructivist theory by $P$. Bourdieu as well as the genealogy of power by M. Foucault as a methodological principle of the sociology of management. According to these concepts, the essence of management is a monopoly on the establishment of symbolic systems of classifications and hierarchies leading to the construction of social groups and the for mation of their identity. Identity is a complex social and cultural phenomenon that includes many representations and appreciation of the past and present in its diversity which is peculiar to society in general and individual social groups in particular. According to modern management theories, culture is an important resource in the development of any community, including territorial, institutional, professional one. In this case, culture is understood as symbolic systems that ensure the interaction of social actors. In the view of Pierre Bourdieu, one of the major parts of management is the implementation of symbolic power in the establishment of social classifications and hierarchies. On the one hand, the identity which forms the social community and is based on collective memory is the result of symbolic systems of public institutions. On the other hand, it originates other symbolic systems that are the basis for the urban symbolic policy, the historical education at schools and universities, the politics of memory. Thus, the review of territorial and local identity as a part of the sociology of management promotes greater awareness of management levels and tools.

Keywords: power, symbolic systems, discursive practices, bodily practices, habitus, constructivism, management, territorial identity, Pierre Bourdieu.

Содержание термина «управление» может быть рассмотрено с разных точек зрения Наиболее часто в научной и учебной литературе можно встретить определение данного термина восходящее к так называемой «традиции Дюркгейма», иначе называемой системным или структурно-функциональным подходом. Согласно этой традиции, управление понимается как деятельность некоего субъекта по упорядочиванию системы и изменению управляемого объекта для достижения некоторой цели. Например, «управление - это целенаправленое воздействие на управляемый объект со стороны субъекта управления в условиях ограничений и в соответствии 
с выбранным критерием эфффективности» [1, с. 38]. Такое определение более свойственно теориям менеджмента, рассматривающего управление с прикладной точки зрения.

С позиции социологии управление включает в себя более широкий круг аспектов, в первую очередь социальных. Управление тут может рассматриваться как организация совместной деятельности людей либо как системный процесс. Например, «что касается управления, то это целесообразная человеческая деятельность, предполагающая решение кардинальных теоретических, методологических и методических проблем: определение объекта и субъекта управления, функций и принципов, стадий управления, его алгоритма, учета прошлого опыта и прогнозирование будущего» [2, с. 38].

Несмотря на то что системный и структурно-функциональный подход является устоявшейся и весьма плодотворной для социологии теоретической традицией, для исследования интересующих нас социальных явлений он мало приспособлен. Поэтому термину «управление» необходимо дать дополнительную интерпретацию. Речь идет о том, чтобы, во-первых, определить то место, которое занимает волнующая нас проблематика (территориальная идентичность и историческая память) в проблемном поле социологии управления, и, во-вторых, отметить методологическую специфрику рассмотрения данной проблемы.

Согласно теории управления, в обществе имеются четыре основных уровня управления:

- национальный,

- регионально-отраслевой,

- территориальный,

- первичный (организация) [3, с. 43].

Внимание социологов при изучении управления в организации чаще сосредоточено на социальном управлении, которое включает в себя такие вопросы, как мотивация труда работников, социальное развитие и социальная деятельность организаций, профессиональные группы и субкультуры, адаптация и социализация работников в организациях, и другие важные аспекты управленческой деятельности.

Данная статья сосредоточена на проблематике территориального управления. Причем в центре внимания работы находятся не механизмы управления городским хозяйством, имуществом или прямая регулятивная деятельность городских институтов власти, а тот аспект управления, который связан с символической деятельностью власти по формированию локальной и региональной общности через конструирование территориальной идентичности и ее важного компонента - исторической памяти. Изучение этого аспекта управления требует методологических установок, отличающихся от широко распространенного в социологии управления системного и структурно-фуннцционального подхода.

Разумеется, ментальные факторы, такие как жизненный опыт, системы мышления, этническая или религиозная культура, ценности, нормы, вообще - человеческий фактор в широком смысле этого слова, учитывались в теории управления практически всегда. Уже в рамках школы научного управления в начале XX в. рассматривались вопросы повышения эффрективности труда за счет стимулирования работников и учета их индивидуальных психофизических особенностей при распределении функционала. Однако в рамках классических теорий управления такие факторы расценивались как нечто объективно заданное, внешнее по отношению к самой организации, вытекающее из объективной биологической и социальной природы человека. Поэтому задача управленца, по мнению представителей научной школы управления, состояла в том, чтобы такие фракторы вычленить и использовать для повышения эффективности работы. Даже в рамках исследований школы человеческих отношений, сменившей школу научного управления, человеческие потребности рассматривались как нечто неизменное. Таким образом, даже знаменитая иерархия потребностей А. Маслоу, психолога, которого также причисляют к школе человеческих отношений, предполагала, что потребности человека заданы фракторами, находящимися вне сферы влияния управленцев, и практически не меняются от общества к обществу. «...Представители рода человеческого движимы множеством потребностей..., потребностью в самоактуализации, т. е. в воплощении заложенных в каждом из нас идиосинкратических и общевидовых потенциалов» [4]. Сегодня такой взгляд представляется несколько упрощенным и вызывает критику, особенно со стороны ученых, решивших проверить его на практике.

Новые теоретические установки, которые позволяют взглянуть на проблемы управления с иной стороны, начали формироваться в 1960-1970-х гг. Этот период историки социальных наук связывают с многочисленными смысловыми «поворотами», предлагающими новую оптику рассмотрения объекта и предмета социальных наук, а точнее - их конструирования, новый подход к фрактам, подлежащим сбору и изучению, новые методы теоретического и эмпирического анализа. В научной литературе можно встретить понятия лингвистического и конструктивистского поворотов. 
В рамках настоящего исследования наиболее важным является возникновение дискурсивного и генетического подходов к анализу социальных феноменов, связанных в первую очередь с именами М. Фуко, П. Бурдье, М. де Серто и некоторых других авторов. Суть их новаций в социальной теории состояла в попытке преодолеть противостояние ранее конкурирующих течений: «традиции Дюркгейма» и «микроинтеракционизма» [5], «структурализма» и «конструктивизма» (в терминологии Бурдье). Опираясь на общие положения лингвистического структурализма и постструктурализма, все эти авторы, во-первых, предлагают рассматривать социальные системы и структуры как результат конструирования различных социальных и политических сил, и в первую очередь государства, либо со стороны «власти»; во-вторых, считают главным инструментом и одновременно итогом такого конструирования символические системы, начиная с календарей и карт, конструирующих социальное время и социальное пространство, и заканчивая принципами социальной классификации. Причем если Фуко видит источник такого конструирования в деперсонализированной «власти» («правительственности» [6, с. 33]), то Бурдье находит его в государстве, точнее в генезисе бюрократического и юридического полей, когда отдельные группы во властном поле выдвигают определения социальных групп общества, которые интериоризируются в сознании населения и начинают восприниматься последним как объективные, как «классы-для-себя» [7, с. 389-405]. Процесс символической борьбы за принципы социальной диффреренциации не может быть остановлен. Результат этой символической борьбы не может быть определен раз и навсегда, он возникает вновь и вновь в каждый момент, когда социальные агенты делают свои ставки в политической игре.

Подчеркнем некоторые принципиальные моменты этого теоретического взгляда.

«Символические системы» могут быть двух типов: произведенные всей группой и произведенные корпусом специалистов или «относительно автономным полем производства и обращения» [8, с. 87-96]. Соотношение между ними Бурдье определяет по аналогии соотношения мифа и религии: первый переходит во вторую вместе с переходом права на символическое производство от любого члена общины к священникам.

Власть слов (идеологий, лозунгов) покоится на «магической вере» в право говорить о мире тех агентов, чьи мнения «считаются более весомыми, чем мнения других людей, так как первые подкреплены наличием соответствующего удостоверения» [9, с. 147], выданного государством, или, как это еще называет Бурдье, символического капитала.

Делегирование государством прав на производство символических систем агентам через наделение их символическим капиталом не означает, что эти агенты являются простыми марионетками в его руках. Во-первых, данное право они реализуют исходя из собственных социальных интересов габитуса, сформированного социальными полями, к которым они принадлежат. Если речь идет об идеологах «доминирующих фракций» господствующего класса, то, по словам Бурдье, они «служат интересам господствующих только по "остаточному принципу"» и «всегда угрожают обернуть к своей пользе власть определять социальный мир». Если же речь идет о более широком слое агентов, наделенных меньшим символическим капиталом, то эти «клерки или “интеллектуалы” и "художники”, в зависимости от эпохи», будут «стремиться поместить на вершину иерархии принципов тот специфический капитал, владение которым обеспечивает их позицию» [10, с. 92-93].

Разумеется, рассмотренные нами авторы были не одинокими в своих суждениях. Близкие теоретические основания, с поправкой на иной предметный контекст исследований, можно обнаружить в социологии наций, социологии образования, например в работе И. Иллича [11], в социологическом рассмотрении социальной политики, в гендерных исследованиях.

Насколько нам известно, несмотря на большую популярность критических теорий вышеуказанных авторов в академическом сообществе и явную схожесть проблематики, которой они занимались, с проблематикой теории управления, их подход достаточно редко применяется в теориях управления, по крайней мере в отечественной социологии. Пожалуй, единственной интерпретацией идей П. Бурдье в поле социологии управления является выделение его теории вкупе с теориями Э. Гидденса и П. Штомпки в деятельностно-активистский подход, определяющий управление как «согласованную систему действий социальных акторов, поддерживающих и конструктивно изменяющих социальный порядок без насилия и манипуляции другими участниками совместной деятельности в контексте данной культурной среды» [12, с. 24].

Вероятно, причины, по которым конструктивизм Бурдье и Фуко не используется в социологии управления в полном объеме, кроются в принадлежности рассматриваемых авторов и авторов, которые определяли и определяют мейнстрим социологии управления, к разным течениям социальной мысли. Если воспользоваться классификацией социологических типов знания, предложенной М. Буравым (М. Burawoy) (профессиональный, критический, прикладной и публичный [13]), то место Бурдье и Фуко находится в сегменте критической и отчасти публичной социологии, в то время как социология управления скорее относится к теоретическому и прикладному 
(т. е. исполняемому по заказу учреждений и организаций). Немаловажную роль в этом играет и неявный критическо-обличительный пафос теорий Бурдье и Фуко, особенно по отношению к так называемой «модернистской» или «либеральной» социологии 1950-х гг., к которой возводит свою родословную современная социология управления и менеджмент.

Чтобы методологический подход Бурдье и Фуко мог быть применен для достижения целей данного исследования, необходимо его операционализировать.

Территориальные общности в современном мире конструируются, как и на заре складывания новоеврепейского государства, через три основные символические системы, создаваемые разными социальными институтами и социальными агентами. Каждая из символических систем, в свою очередь, реализуется через свой специфический набор практик.

Первая система - это набор территориально-административных маркеров, обеспечивающих фрормальное разграничение территорий и проживающего на них населения. Наиболее наглядным ее примером является карта. Действительно, говорим ли мы об общегражданской или региональной/локальной идентичности, первым шагом к конструированию общности будет демаркация границ, в рамках которых администрирующие институты имеют право осуществлять свою власть. К элементам этой символической системы мы должны отнести также символическое оформление этих границ, от пограничного столба до стелы, обозначающей въезд в регион или город, институты регистрации, территориальную топонимику, как правило дающую имя проживающим на территории людям (например, «пермяки», «жители Ленинского района» и т. д.). Административная карта является репрезентацией территориального фррейма, рамки, без которой не могут осуществляться повседневные практики управления и на основании которой властные институты и агенты ежедневно утверждают свое право осуществлять власть через указания, инструкции, выдачу необходимых справок и т. д. Ничто так хорошо не запечатлевает в сознании людей их принадлежность к региону, городу или государству, как приказы и проверки, посылаемые «сверху», или справки, за которыми необходимо обращаться в соответствующие органы, наделенные центром особыми полномочиями как раз по территориальному принципу.

Второй символической системой, конструирующей территориальную идентичность, являются различные вербальные и иконические знаковые подсистемы, обеспечивающие коммуникацию, доступную жителям этой территории, и одновременно отсекающие «другого». Самым простым и понятным примером вербальной подсистемы для государства является официальный язык, культивируемый государственной школой, средствами массовой информации, сферой искусства [14]. Для региона или отдельного города такой вербальной системой становится местный диалект.

Замечательным примером конструирования местного диалекта является издание «Попермски говоря. Словарь пермских слов и выражений», появившееся на свет в 2013 г. [15] и с тех пор неоднократно переизданное. В его составлении участвовали пермские диалектологи, он издан Информационным туристическим центром при поддержке Министерства культуры Пермского края. Из 310 лексических единиц, собранных в нем, часть имеет этнографическое происхождение, часть можно отнести к городским социолектам. Как справедливо замечают многочисленные комментаторы этого словаря из числа самих пермяков, большинство слов легко можно найти и в других соседних регионах, а часть имеет более узкое хождение. Однако это не мешает книге пользоваться большой популярностью: сам фракт провозглашения некоего набора слов «пермским языком» вызывает массу положительных эмоций у большинства читателей и помогает конструировать городскую и региональную идентичность. Кстати, аналогичные популярные подборки «местных словарей» получили достаточно широкое распространение в социальных сетях и на городских интернет-фрорумах.

Немаловажной практикой утверждения локальных идентичностей через символическую вербальную систему является контент средств массовой информации, который, как правило, привязан к территории. Это особенно заметно в СМИ, имеющих региональную и муниципальную привязку (новости и реклама тут строго территориальные). Не являются исключением и федеральные СМИ: как правило, в них присутствуют региональные вкладки (газеты) либо местные новости и реклама (электронные СМИ) [16].

К иконическим знаковым подсистемам можно отнести геральдические знаки, гербы, логотипы и иные изображения, маркирующие территорию.

И, наконец, третьей символической системой выступает историческая память, которая, на наш взгляд, является самым важным компонентом конструирования территориальных идентичностей. Она составляет основу для символической политики администраций, воплощаясь в памятниках и памятных топонимах. На основе исторической памяти фрункционируют коммеморативные ритуалы, инициируемые властью или даже существующие помимо нее. Историческая па- 
мять существует и в нарративах, которые могут быть как официально утвержденными, так и неофициальными (семейные истории, легенды, анекдоты и т. д.). Историческая память тесно связана с развитием чувства «малой родины», которое, как правило, обретается еще в детстве.

\section{Ссылки:}

1. Михненко П.А. Теория менеджмента : учебник. 2-е изд., перераб. и доп. М., 2014. 640 с

2. Тощенко Ж.Т. Социология управления : учебник. М., 2011. 300 с.

3. Захаров Н.Л., Кузнецов А.Л. Управление социальным развитием организации : учебник. М., 2006.263 с.

4. Маслоу А. Мотивация и личность. 3-е изд. СПб., 2008. 352 с.

5. Коллинз Р. Четыре социологических традиции. М., 2009. 320 с.

6. Бикбов А. Как делается государство // Бурдье П. О государстве : курс лекций в Коллеж де Франс (1989-1992). М., 2016. $720 \mathrm{c}$.

7. Бурдье П. О государстве. С. 389-405.

8. Там же. С. 87-96.

9. Бурдье П. Социальное пространство и символическая власть // THESIS. 1993. Вып. 2. С. 137-150.

10. Бурдье П. О символической власти // Бурдье П. Социология социального пространства. М. ; СПб., 2007. С. 87-96.

11. Illich I. Deschooling Society. N. Y., 1970. 186 p.

12. Тощенко Ж.Т. Указ. соч. С. 24.

13. Буравой М. За публичную социологию // Общественная роль социологии / под ред. П. Романова, Е. Ярской-Смирновой. М., 2008. С. 8-51.

14. Андерсон Б. Воображаемые сообщества. Размышления об истоках и распространении национализма / пер. с англ. В.Г. Николаева. М., 2001. 288 с. ; Геллнер Э. Нации и национализм : пер. с англ. / ред. и послесл. И.И. Крупника. М., 1991. 126 c.

15. По-пермски говоря. Словарь пермских слов и выражений. Пермь, 2013.

16. Дубин Б.В. Интеллектуальные группы и символические формы: очерки социологии современной культуры. М., 2004. 348 c. 